\title{
26
}

\section{Dynamics of the Sundarbans Mangroves in Bangladesh Under Climate Change}

\author{
Anirban Mukhopadhyay, Andres Payo, \\ Abhra Chanda, Tuhin Ghosh, \\ Shahad Mahabub Chowdhury, and Sugata Hazra
}

\subsection{Introduction}

Mangroves are the third most productive and bio-diverse ecosystem in the world, followed by the tropical rain forests and the coral reefs (Lang'at and Kairo 2008). They are mostly confined to the tropics and subtropics covering approximately 75 per cent of the world's coastline between $25^{\circ} \mathrm{N}$ and $25^{\circ} \mathrm{S}$ (Borges et al. 2003). Mangroves provide a wide range of ecosystem services ranging from mitigation of global climate change by carbon capture to the sustenance of local communities, especially locally poor people (e.g. fishermen, honey collectors, etc.) whose livelihood depends upon the mangrove forest products (see Chap. 23). Operating as a natural barrier to hazards such

A. Mukhopadhyay $(\bowtie) \bullet$ A. Chanda $\bullet$ T. Ghosh $\bullet$ S. Hazra School of Oceanographic Studies, Jadavpur University, Kolkata, India

A. Payo

British Geological Survey, Keyworth, Nottingham, UK

S. M. Chowdhury

International Union for Conservation of Nature, Dhaka, Bangladesh

(C) The Author(s) 2018

489

R. J. Nicholls et al. (eds.), Ecosystem Services for Well-Being in Deltas,

https://doi.org/10.1007/978-3-319-71093-8_26 
as tropical cyclones and tsunamis, mangroves also help in the protection of shoreline areas and prevent coastal erosion (Das and Vincent 2009). Additionally, they act as biological filters, maintaining water quality in coastal regions and providing nursing grounds for a number of diverse flora and fauna species particularly fish. However, mangroves are extremely sensitive to changing environmental conditions which make these ecosystems highly endangered around the globe (Hutchison et al. 2014). Around one-third of the world's mangroves have been lost in the last 50 years (Alongi 2002), and some scientists have suggested that the entire mangrove community might be lost by the end of the twenty-first century (Duke et al. 2007). The need for assessment of mangrove forest trends in the context of global change is therefore paramount (Polidoro et al. 2010; Duke et al. 2007; Spencer et al. 2016).

The Sundarbans, situated between $88^{\circ} 55^{\prime} \mathrm{E}$ to $89^{\circ} \mathrm{E}$ and $21^{\circ} 30^{\prime} \mathrm{N}$ to $23^{\circ} 30^{\prime} \mathrm{N}$, comprise the world's largest single block of mangrove forest. The region is estimated to have come into existence 4000 years ago (Ali $1998)$ and is shared between India $\left(4,000 \mathrm{~km}^{2}\right)$ and Bangladesh $\left(6,000 \mathrm{~km}^{2}\right)$. In 1996, the entire Bangladesh Sundarbans mangroves were declared a 'reserve forest' and, in 1997, were designated as a 'UNESCO World Heritage Site'. ${ }^{1}$ The Sundarbans Reserve Forest (SRF) is home to around 700 species of flora and fauna giving shelter to a number of endangered species, notably the Royal Bengal Tiger (Panthera tigris) (Rahman 2009). Income generated from the forest ecosystem services is extremely important, accounting for 74 per cent and 48 per cent of total household income for lower- and middle-income households residing in some areas of the Sundarbans (Abdullah et al. 2016). This implies that the forest produces play a major role in the poverty alleviation of the local communities, particularly those people who are exclusively dependent on the forest derived products for their livelihood.

This chapter highlights the potential impacts that the Bangladesh Sundarbans ecosystem (Fig. 26.1) faces in the future due to ongoing sealevel rise and climate change and suggests responses that should be taken into account when framing suitable policy options. These options are based on assessing the extent of forest cover and changing species composition associated with physical change and its consequences for forest carbon stocks and ecosystem services that would affect the livelihood of the local communities. 

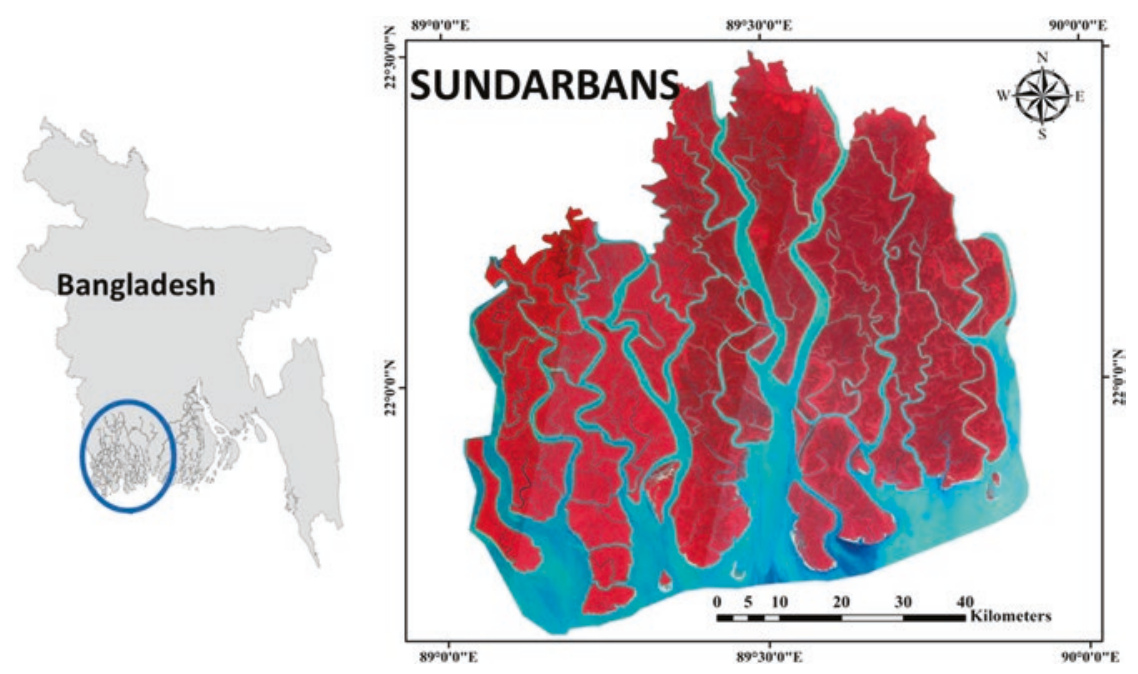

Fig. 26.1 Map showing the extent of the Bangladesh Sundarbans study area

\subsection{Climate Change and Mangroves}

In order to assess the effect of climate change on the mangroves of Bangladesh Sundarbans, two principal approaches were adopted for the present research. One discusses the Bangladesh Sundarbans after a century of geomorphological change under three different sea-level rise scenarios using the Sea Level Affecting Marshes Model (SLAMM) model (Sect. 26.2.1). This focusses on physical land loss due to inundation and erosion associated with projected sea-level rise. Secondly, potential changes in species assemblage during this century, and hence the blue carbon stock and ecosystem services, are identified under the Business As Usual (BAU) scenario using a hybrid model of cellular automata and Markov chain (Sects. 26.2.2, 26.2.3 and 26.3). This research emphasises that mangrove loss is not exclusively associated with extent but also due to changes in the species composition and loss.

\subsubsection{Effects of Regional Sea-Level Rise}

With global mean sea-level rise projected as up to $0.98 \mathrm{~m}$ or greater by 2100 relative to the baseline period (1985-2005), the Sundarbansmean elevation currently approximately $2 \mathrm{~m}$ above mean sea level-is 
at risk from inundation and subsequent wetland loss; however the magnitude of loss remains unclear. Huq et al. (1995) suggested that 'one meter rise in mean sea level will probably lead to the destruction of the Sundarbans by its complete inundation'. Loucks et al. (2010) estimated that most of the Sundarbans in Bangladesh will be overwhelmed with a rise in sea level of $0.28 \mathrm{~m}$ over the next $50-90$ years assuming no change in the local net rate of sea-level rise of 4-7.8 mm/year. More recently, based on the concept of the loss of 'elevation capital' (the potential of a mangrove ecosystem to remain within a suitable inundation regime between highest astronomical tide (HAT) and mean sea level (MSL)), Lovelock et al. (2015) suggested that the Sundarbans will be able to sustain itself beyond the year 2100 even under high rates of sea-level rise (1.4 $\mathrm{m}$ by 2100$)$. Thus it is clear there is no consensus on the future of the Bangladesh Sundarbans under sea-level rise by the end of this century.

To address this uncertainty remote sensing data and field measurements, geographic information systems and simulation modelling are applied to investigate the potential effects of different sea-level rise scenarios on the Sundarbans (Fig. 26.2). Assuming that MSL is a better proxy for mangrove area delineation, the SLAMM model is able to reproduce the observed area losses for the period 2000-2010 (Payo et al. 2016). Using this calibrated model, the estimated mangrove area net losses (relative to year 2000) are estimated to be $81-178 \mathrm{~km}^{2}$ (two to five per cent), $111-376 \mathrm{~km}^{2}$ (three to ten per cent) and $583-1393 \mathrm{~km}^{2}$ (15-37 per cent) for sea-level rise scenarios to 2100 of $0.46 \mathrm{~m}, 0.75 \mathrm{~m}$ and $1.48 \mathrm{~m}$, respectively, with net subsidence of $\pm 2.5 \mathrm{~mm} /$ year. Where relative sea-level rise is less than $0.75 \mathrm{~m}$, these area losses are very small (less than ten per cent of present day mangrove area of $3,778 \mathrm{~km}^{2}$ ) and significantly smaller than Lovelock et al. (2015) has suggested. Simulations also suggest that erosion rather than inundation may remain the dominant loss driver to 2100 under certain scenarios. Only under the highest scenarios of relative sea-level rise does inundation due to sea-level rise become the dominant loss process, suggesting that the mangrove system will persist until 2100 . 
Net Subsidence

SLR

$46 \mathrm{~cm}$

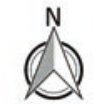

$75 \mathrm{~cm}$

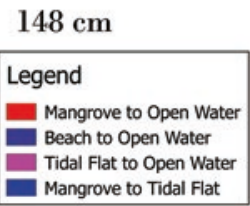

$-2.5 \mathrm{~mm} /$ year
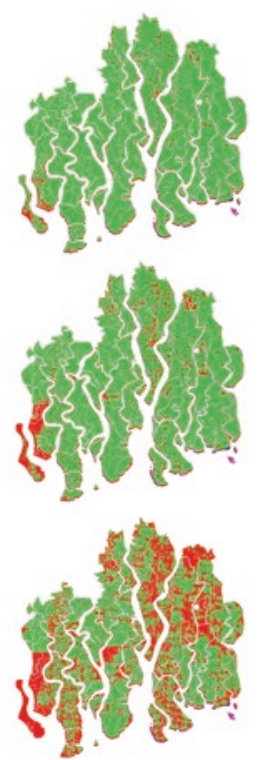

$0 \mathrm{~mm} /$ year
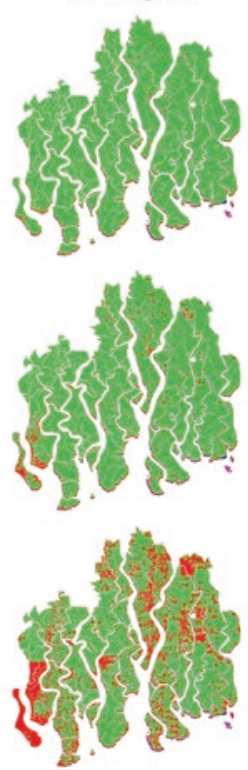

$+2.5 \mathrm{~mm} /$ year
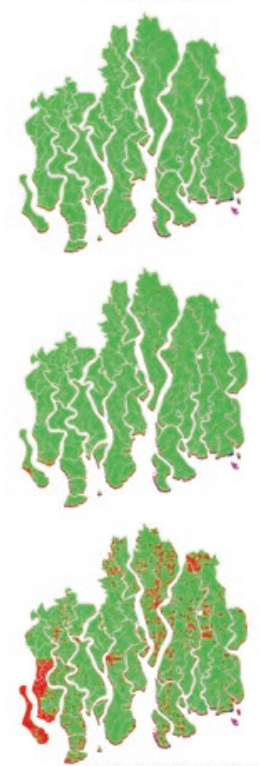

$10010203040 \mathrm{~km}$

Fig. 26.2 Simulated mangrove area losses by the year 2100 under nine different relative sea-level rise scenarios (see also Payo et al. (2016))

\subsubsection{Species Assemblage Change}

One of the most salient aspects of the Bangladesh Sundarbans mangrove ecosystem is its rich species diversity. The wide variety of floral species in this ecosystem largely accounts for the overall high biodiversity of this region. This high heterogeneity makes characterising the species assemblage and predicting future trends a challenging task.

Analysis of the spatial distribution of mangrove species assemblages is carried out by implementing a hybrid model of Markov chain and cellular automata in business as usual scenario (detailed methodology can be found in Mukhopadhyay et al. 2015). Results show that species distribution will alter substantially within a hundred years alongside a significant decrease in the forest cover area (Fig. 26.3). The areal distribution 


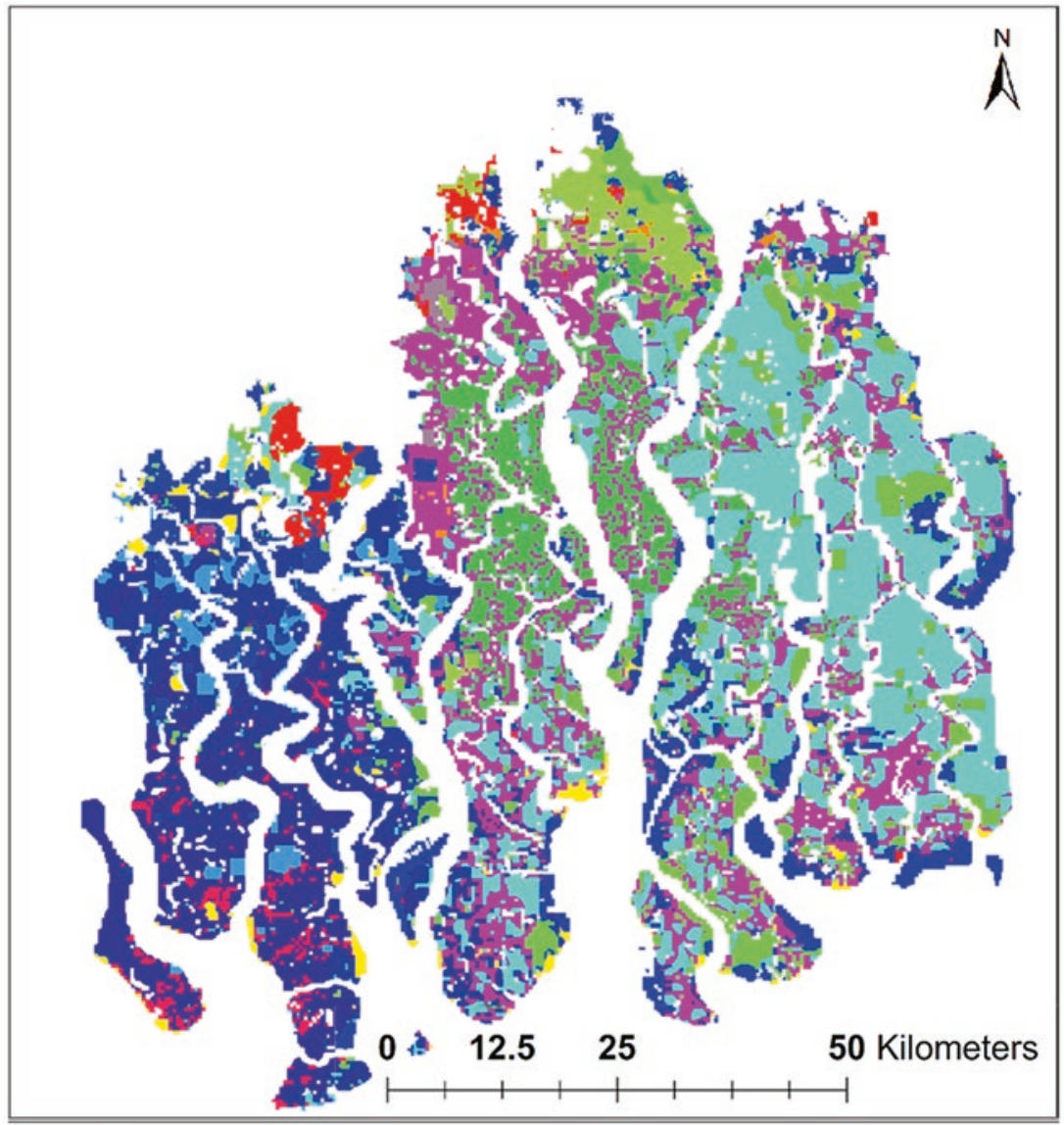

\section{Legend}

\begin{tabular}{l}
\hline Avicennia \\
Sand bars \& mudflat \\
Heritiera dominated \& Xylocarpus \& Bruguiera \\
Heritiera \\
Heritiera dominated \& Xylocarpus \\
Xylocarpus dominated \& Bruguiera \& Avicennia \\
Mixed \\
Xylocarpus dominated \& Bruguiera
\end{tabular}

Grass and Bare Ground

Sonneratia

Excoecariadominated \& Ceriops

Ceriops dominated \& Excoecaria

Heritieradominated \& Excoecaria

Ceriops

Excoecaria

Excoecariadominated \& Heritiera

Fig. 26.3 Species assemblages of Bangladesh Sundarbans after 2100 (see also Mukhopadhyay et al. (2015)) 
of species assemblages with the following dominant species decrease in this order: (1) Goran (Ceriops) (2) Sundari (Heritiera), (3) Passur (Xylocarpus) and (4) Baen (Avicennia). On the other hand, assemblages with the following dominant species are predicted to increase: (1) Gewa (Excoecaria), (2) Keora (Sonneratia) and (3) Kankra (Bruguiera). This is potentially related to changes in salinity patterns. Karim (1988) and Hoque et al. (2006) previously differentiated the salinity zones of the Sundarbans into low saline (Oligohaline), moderate saline (Mesohaline) and high saline (Polyhaline) zones. Based on these categories and within the overall decline of 17 per cent of forest area, it is observed that the freshwater-dependent mangroves like that of Heritiera (Oligohaline) would diminish in abundance while there is an increase in the moderate to high salt-tolerant species such as Excoecaria, Avicennia and Bruguiera.

As mentioned earlier, within the next 100 years, almost one-fifth (17 per cent) of the existing forest would disappear from this ecosystem, under the BAU scenario. Extreme episodic events (e.g. cyclonic disaster, tsunami, etc.), which are not taken into account in this study, might make the scenario worse. Apart from the forest cover loss, the modelled output also highlights that low saline species along with their characteristic produce and ecosystem services would decline in future.

It is important to note that the predictions, as discussed in Mukhopadhyay et al. (2015), assume that the trend of environmental factors such as salinity, temperature, rainfall and sea-level rise leading to these changes will remain the same for the next few decades. However, with the anticipated accelerating changes in the previously mentioned controlling factors, these impacts may be underestimates.

\subsubsection{Blue Carbon Stock}

Forests, including mangroves, are acknowledged to play a crucial role in mitigating global climate change. Mangroves constitute rich soil carbon content up to several metres depth (Donato et al. 2011) and a high belowground carbon content in their root system in comparison to other tropical 
forests (Lovelock 2008). They therefore have high rates of carbon sequestration in both above- and below-ground live biomass (Alongi 2012).

Chanda et al. (2016) assessed the changes in the Bangladesh Sundarbans's blue carbon stock (i.e. the carbon captured by ocean and coastal ecosystems in the form of biomass and sediments) over the last 30 years and, based on observed trends, generated a plausible scenario of the future carbon stock (after a hundred years). Applying this scenario with a hybrid model of Markov chain and cellular automata (a similar approach can be found in Mukhopadhyay et al. 2015), the change in blue carbon stock is assessed. The magnitude of the above- and below-ground biomass of the various prominent species assemblages at present was acquired from Rahman et al. (2015), and the carbon concentration of the various species was measured by sampling in selected points. Combining these datasets, the total blue carbon stock of all the species composition classes was estimated (see Mukhopadhyay et al. (2015) for details). At present, $36.24 \mathrm{Tg} \mathrm{C}^{2}$ is stored above ground and $54.95 \mathrm{Tg} \mathrm{C}$ below ground in this forest resulting in a total blue carbon stock of $91.19 \mathrm{Tg} \mathrm{C}$. According to the modelling, $15.88 \mathrm{Tg} \mathrm{C}$ (17.4 per cent of current capacity) would be lost from the area by the year 2115 .

The low saline Heritiera-dominated species composition classes currently account for the major portion of the carbon sock (45.60 Tg C; almost 50 per cent of the total carbon stock), while the remainder is locked up in the moderate to high saline species. The predictions revealed that almost $22.42 \mathrm{Tg} \mathrm{C}$ would be lost from low saline regions accompanied by an increase of $8.20 \mathrm{Tg} \mathrm{C}$ in the high saline regions dominated mainly by Excoecaria and Avicennia. Low saline mangrove species are capable of higher carbon sequestration and photosynthetic carbon assimilation compared to those that thrive in high saline zones (Rahman et al. 2015; Nandy and Ghose 2001). As already shown, due to the anticipated changes in salinity, this class of species would be most affected leading to a net forest carbon loss of $15.88 \mathrm{Tg} \mathrm{C}$, and the increase in the moderate to high saline mangroves is insufficient to counterbalance the blue carbon loss from the low saline regions (Fig. 26.4). Hence, a substantial net forest area loss along with the 

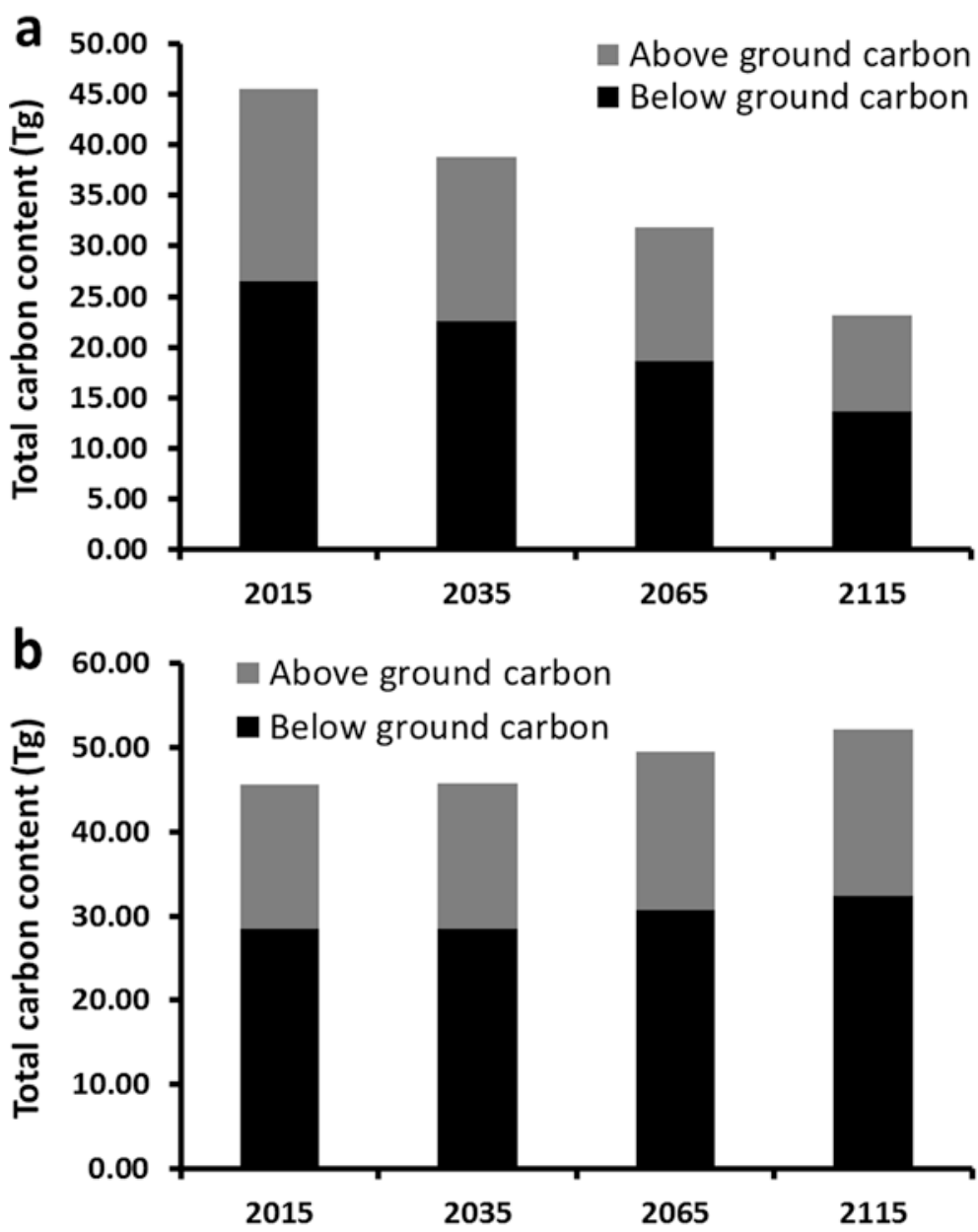

Fig. 26.4 Present and predicted trend of total carbon content in the (a) low saline and (b) moderate to high saline zones

changes in species assemblage accompanied by carbon dioxide $\left(\mathrm{CO}_{2}\right)$ emission of $1121 \mathrm{Mg} \mathrm{CO}_{2}$ ha/year is anticipated over the next 100 years. At the current cost of new atmospheric carbon (Polidoro et al. 2010), almost US $\$ 2.26$ billion worth of carbon will be lost from the Bangladesh Sundarbans by the year 2115 . 


\subsection{Sundarbans Mangrove Ecosystem Services}

Although mangroves are known for a wide range of ecosystem services, there have been few attempts to quantify and predict the future benefits provided by these ecosystems to both human beings and the climate as a whole. The Millennium Ecosystem Assessment classification of ecosystem services is probably the most well-known classification scheme (MEA 2005). The Sundarbans mangrove ecosystem services include provisioning, for example, food, fuel wood, protection and a nursery for fish and crustaceans, and regulating/supporting, for example, by providing security to coastal communities from cyclones, wind action, wave action and currents and reducing damages to housing, infrastructure and food sources by reducing saline water intrusion. The mangroves also help to stop erosion as roots hold sediments in place and maintain the biotic water quality of the region, which in turn helps the fishing community. Another service extended by these mangroves include items like timber, fuel wood, thatching materials, honey and waxes, thus supporting the local as well as the national economy (see Chaps. 2 and 23). More than 200 tonnes of honey and 50 tonnes of beeswax are harvested per year from the Bangladesh Sundarbans under the supervision of Forest Department. The Sundarbans accounts for about 50 per cent of the honey produced in Bangladesh (Gani 2001). By also providing cultural services and having recreational values in the form of eco-tourism, the Sundarbans mangrove ecosystem is one of the most valued ecosystems of the world.

Based on the changes predicted in species assemblages (Sect. 26.2.2), it can be observed that species like Heritiera and Ceriops are likely going to reduce in future, whereas the abundance of species like Excoecaria and Bruguiera would increase. This implies that in the future, this ecosystem will not be able to provide the beneficial services such as high carbon sequestration rate (Nandy and Ghose 2001), good timber and a few traditional uses of medicine (which is the speciality of Heritiera and Ceriops). There is also likely to be a decline in the regulating and supporting services like storm protection, shoreline protection and enhanced primary productivity. On the other hand, with increasing abundance of Excoecaria 
and Bruguiera, products from these species such as soft wood for making furniture and ornaments and medicinal values such as anti-tumour promoting drugs (Konoshima et al. 2001) would be better utilised. Increases in Excoecaria and Bruguiera might also be beneficial for ecosystem services such as soil formation and retention along with organic matter and nutrient enrichment in the forest floor. However, on the whole since the forest extent is predicted to decline by the end of 2100 , the magnitude of ecosystem services is expected to decline, especially from those species which are less salt tolerant.

\subsection{Management Strategy and Policy Framing}

The foremost outcome that is evident from this research is that the mangrove forest cover of Bangladesh Sundarbans is expected to reduce in the future, although not at the alarming rate predicted by previous studies. The most adverse effects of this reduction in mangrove area would be the loss in both quality and quantity of ecosystem services that this ecosystem provides to the local community. In order to compensate for this loss in the main reserve forest area, substantial afforestation is required in the fringe areas and the less vulnerable areas of the forest. Although this kind of afforestation is already underway, local communities could be made more aware of it and their participation in such programmes encouraged. Also, instead of the current mono-species culture, afforestation programmes should be envisaged in such a way that the species diversity and heterogeneity of this ecosystem remain conserved. Special emphasis may be given to the freshwater-loving species like Heritiera and Ceriops in favourable locations. Mangrove plantation efforts could also be undertaken more in non-forest areas creating a toe line bio-shield for existing embankments.

This re-afforestation would not only strengthen the ecosystem's carbon and biomass stock but also provide easily available forest products which could be utilised by the local poor people for their daily life sustenance and serve as an alternative livelihood option. At present, among the various ecosystem services that this forest provides, collection of honey along with 
wax are very crucial livelihood options for extremely poor people. In the future, the climate change-driven mangrove forest cover loss could substantially hamper natural production of honey and wax, accentuating the man-animal conflict during honey collection. It may therefore be advisable to promote apiculture in the vicinity of settlements as well as in the core forest areas as a sustainable livelihood option for the local population. This would ensure not only a secure income but the incidences of injury or even casualty during honey collection could be avoided.

A substantial amount of carbon is stored in the forest of Bangladesh Sundarbans at present. This sequestration can play a crucial role in combating the anthropogenic increase of $\mathrm{CO}_{2}$ in the atmosphere. The natural performance of this mangrove ecosystem which in turn is beneficial to the global climate might be developed as a wealth-creating instrument under a well-functioning, well-informed market mechanism. However, unless a market mechanism, conferring rights to the forest-dependent community to trade carbon credit to the global community, is developed, sustainable development in the delta will remain elusive.

\section{Notes}

1. See http://whc.unesco.org/en/list/798

2. $1 \mathrm{Tg} \mathrm{C}=1$ Teragram carbon $=10^{9} \mathrm{~kg}$ carbon.

\section{References}

Abdullah, A.N.M., N. Stacey, S.T. Garnett, and B. Myers. 2016. Economic dependence on mangrove forest resources for livelihoods in the Sundarbans, Bangladesh. Forest Policy and Economics 64: 15-24. https://doi.org/10.1016/j. forpol.2015.12.009.

Ali, S.S. 1998. Sundarbans: Its resources and eco-system. Proceedings of the national seminar on Integrated Management of Ganges Flood Plains and Sundarbans Ecosystem, 16-18 July 1994, Khulna University, Khulna.

Alongi, D.M. 2002. Present state and future of the world's mangrove forests. Environmental Conservation 29 (3): 331-349. https://doi.org/10.1017/ s0376892902000231. 
2012. Carbon sequestration in mangrove forests. Carbon Management 3 (3): 313-322. https://doi.org/10.4155/cmt.12.20.

Borges, A.V., S. Djenidi, G. Lacroix, J. Theate, B. Delille, and M. Frankignoulle. 2003. Atmospheric $\mathrm{CO}_{2}$ flux from mangrove surrounding waters. Geophysical Research Letters 30 (11). https://doi.org/10.1029/2003gl017143.

Chanda, A., A. Mukhopadhyay, T. Ghosh, A. Akhand, P. Mondal, S. Ghosh, S. Mukherjee, J. Wolf, A.N. Lázár, M.M. Rahman, M. Salehin, S.M. Chowdhury, and S. Hazra. 2016. Blue carbon stock of the Bangladesh Sundarbans mangroves: What could be the scenario after a century? Wetlands 36 (6): 1033-1045. https://doi.org/10.1007/s13157-016-0819-7.

Das, S., and J.R. Vincent. 2009. Mangroves protected villages and reduced death toll during Indian super cyclone. Proceedings of the National Academy of Sciences of the United States of America 106 (18): 7357-7360. https://doi. org/10.1073/pnas.0810440106.

Donato, D.C., J.B. Kauffman, D. Murdiyarso, S. Kurnianto, M. Stidham, and M. Kanninen. 2011. Mangroves among the most carbon-rich forests in the tropics. Nature Geoscience 4 (5): 293-297. https://doi.org/10.1038/ngeo1123. Duke, N.C., J.-O. Meynecke, S. Dittmann, A.M. Ellison, K. Anger, U. Berger, S. Cannicci, K. Diele, K.C. Ewel, C.D. Field, N. Koedam, S.Y. Lee, C. Marchand, I. Nordhaus, and F. Dahdouh-Guebas. 2007. A world without mangroves? Science 317 (5834): 41-42. https://doi.org/10.1126/science.317.5834.41b.

Gani, M.O. 2001. The giant honeybee (Apis dorsata) and honey hunting in Sundarbans reserved forests of Bangladesh. Apimondia 2001: Proceedings of the 37th International Apicultural Congress, 28 October-1 November, Durban. Hoque, M.A., M.S.K.A. Sarkar, A.S.K.U. Khan, M.A.H. Moral, and A.K.M. Khurram. 2006. Present status of salinity rise in Sundarbans area and its effect on Sundari (Heritiera fomes) species. Research Journal of Agriculture and Biological Sciences 2 (3): 115-121.

Huq, S., S.I. Ali, and A.A. Rahman. 1995. Sea-level rise and Bangladesh: A preliminary analysis. Journal of Coastal Research SI 14: 44-53.

Hutchison, J., A. Manica, R. Swetnam, A. Balmford, and M. Spalding. 2014. Predicting global patterns in mangrove forest biomass. Conservation Letters 7 (3): 233-240. https://doi.org/10.1111/conl.12060.

Karim, A. 1988. Environmental factors and the distribution of mangroves in the Sundarbans with special reference to Heritiera fomes. Ph.D. thesis, University of Calcutta.

Konoshima, T., T. Konishi, M. Takasaki, K. Yamazoe, and H. Tokuda. 2001. Anti-tumor-promoting activity of the diterpene from Excoecaria agallocha. II. Biological and Pharmaceutical Bulletin 24 (12): 1440-1442. https://doi. org/10.1248/bpb.24.1440. 
Lang'at, J.K., and J.G. Kairo. 2008. Conservation and management of mangrove forests in Kenya. Mangrove Reforestation Program. Mombasa: Kenya Marine and Fisheries Research Institute. www.wrm.org.uy/...on_and_managemen_ mangrove_Kenya.pdf. Accessed 5 May 2016.

Loucks, C., S. Barber-Meyer, M.A.A. Hossain, A. Barlow, and R.M. Chowdhury. 2010. Sea level rise and tigers: Predicted impacts to Bangladesh's Sundarbans mangroves. Climatic Change 98 (1-2): 291-298. https://doi.org/10.1007/ s10584-009-9761-5.

Lovelock, C.E. 2008. Soil respiration and belowground carbon allocation in mangrove forests. Ecosystems 11 (2): 342-354. https://doi.org/10.1007/ s10021-008-9125-4.

Lovelock, C.E., D.R. Cahoon, D.A. Friess, G.R. Guntenspergen, K.W. Krauss, R. Reef, K. Rogers, M.L. Saunders, F. Sidik, A. Swales, N. Saintilan, L.X. Thuyen, and T. Triet. 2015. The vulnerability of Indo-Pacific mangrove forests to sea-level rise. Nature 526 (7574): 559-U217. https://doi. org/10.1038/nature 15538 .

MEA. 2005. Ecosystems and human well-being: Synthesis. Millennium Ecosystem Assessment (MEA). Washington, DC: Island Press. http://www.millenniumassessment.org/documents/document.356.aspx.pdf. Accessed 1 Aug 2016. Mukhopadhyay, A., P. Mondal, J. Barik, S.M. Chowdhury, T. Ghosh, and S. Hazra. 2015. Changes in mangrove species assemblages and future prediction of the Bangladesh Sundarbans using Markov chain model and cellular automata. Environmental Science-Processes and Impacts 17 (6): 1111-1117. https://doi.org/10.1039/c4em00611a.

Nandy, P., and M. Ghose. 2001. Photosynthesis and water-use efficiency of some mangroves from Sundarbans, India. Journal of Plant Biology 44 (4): 213-219. Payo, A., A. Mukhopadhyay, S. Hazra, T. Ghosh, S. Ghosh, S. Brown, R.J. Nicholls, L. Bricheno, J. Wolf, S. Kay, A.N. Lázár, and A. Haque. 2016. Projected changes in area of the Sundarbans mangrove forest in Bangladesh due to SLR by 2100. Climatic Change: 1-13. https://doi.org/10.1007/ s10584-016-1769-z.

Polidoro, B.A., K.E. Carpenter, L. Collins, N.C. Duke, A.M. Ellison, J.C. Ellison, E.J. Farnsworth, E.S. Fernando, K. Kathiresan, N.E. Koedam, S.R. Livingstone, T. Miyagi, G.E. Moore, N.N. Vien, J.E. Ong, J.H. Primavera, S.G. Salmo, J.C. Sanciangco, S. Sukardjo, Y.M. Wang, and J.W.H. Yong. 2010. The loss of species: Mangrove extinction risk and geographic areas of global concern. PLoS One 5 (4). https://doi.org/10.1371/ journal.pone.0010095. 
Rahman, M.M., M.N.I. Khan, A.K.F. Hoque, and I. Ahmed. 2015. Carbon stock in the Sundarbans mangrove forest: spatial variations in vegetation types and salinity zones. Wetlands Ecology and Management 23 (2):269-283. https://doi.org/10.1007/s11273-014-9379-x Licence journal article.

Spencer, T., M. Schuerch, R.J. Nicholls, J. Hinkel, D. Lincke, A.T. Vafeidis, R. Reef, L. McFadden, and S. Brown. 2016. Global coastal wetland change under sea-level rise and related stresses: The DIVA Wetland Change Model. Global and Planetary Change 139: 15-30. https://doi.org/10.1016/j. gloplacha.2015.12.018.

Open Access This chapter is licensed under the terms of the Creative Commons Attribution 4.0 International License (http://creativecommons.org/licenses/ by/4.0/), which permits use, sharing, adaptation, distribution and reproduction in any medium or format, as long as you give appropriate credit to the original author(s) and the source, provide a link to the Creative Commons license and indicate if changes were made.

The images or other third party material in this chapter are included in the chapter's Creative Commons license, unless indicated otherwise in a credit line to the material. If material is not included in the chapter's Creative Commons license and your intended use is not permitted by statutory regulation or exceeds the permitted use, you will need to obtain permission directly from the copyright holder.

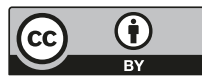

